\title{
Electronic Cigarettes Regulation in the UK: A Case Study in Evidence Informed Policy Making
}

Benjamin Hawkins

\section{INTRODUCTION}

Electronic cigarettes (e-cigarettes) are hand-held, battery-operated devices, in which liquid nicotine is vapourised and inhaled by the user. E-cigarettes vary greatly in form and appearance, with some products (known as 'cigalikes') closely resembling conventional cigarettes in shape and appearance. Larger, refillable devices (known as 'eGos' or 'mods') bear little visual similarity to tobacco products (Zhu et al. 2014; Grana et al. 2014a). The latter offer the possibility for users to vary rates of nicotine delivery through adjustable settings, customisation and the concentration of nicotine solution ('e-liquid') used. Globally, transnational tobacco corporations (TTCs) have aggressively entered the sector through a series of mergers and acquisitions (Manning 2013; Richtel 2013; McNeill and Munafò 2013; Tobacco Tactics 2014a) and the once highly disparate e-cigarette market is rapidly

\footnotetext{
B. Hawkins $(\bowtie)$

London School of Hygiene and Tropical Medicine, London, UK e-mail: ben.hawkins@lshtm.ac.uk

(C) The Author(s) 2018

J. Parkhurst et al. (eds.), Evidence Use in Health Policy Making, International Series on Public Policy, https://doi.org/10.1007/978-3-319-93467-9_7
} 
consolidating around a small number of producers, linked to TTCs (Smithers 2014; Thesing 2014).

Studies indicate that use of e-cigarettes doubled in Europe and North America between 2008 and 2012 (Grana et al. 2014a). The rapid expansion in the use and marketing of these products raised a number of regulatory issues including their classification (as consumer products or medical devices), and thus the ways in which they can be sold and marketed, and restrictions on their purchase (age limits and outlet types) and use (in public places) (World Health Organization 2014). As the popularity and promotion of e-cigarettes grew, national governments and the European Union (EU) sought to put in place effective rules governing their sale, use and marketing, which balance the potential benefits of e-cigarettes (primarily for existing smokers who may use them as quit aids) against the need to protect consumers and the wider public's health.

Policy decisions such as how to regulate e-cigarettes require responsible agencies to evaluate the likely impact and potential risks of novel products, through engagement with the relevant bodies of evidence. In the case of e-cigarettes, this process was complicated by the limited evidence base on the health effects of e-cigarettes in real world conditions or their patterns of use and the significant divisions which have emerged within the tobacco control and public health communities regarding e-cigarettes (cf. Etter 2013; Chapman 2013; Chapman et al. 2017; McNeill et al. 2015a; McKee and Capewell 2015a). Those in favour on e-cigarettes emphasise their potential usefulness as smoking cessations tools, and emphasise that e-cigarettes offer a market oriented and demand led solution to smoking. Consequently they support non-interventionist regulatory frameworks which facilitate the development of the product category and their appeal to smokers. Against this, those concerned about the potentially negative externalities of e-cigarettes for population level health have advocated policy makers adopt the precautionary principle and more robust controls on the sale, marketing and use of e-cigarettes. This schism has seen two separate letters sent to WHO DirectorGeneral, Margaret Chan, setting out the potential benefits and dangers of e-cigarettes respectively, and advocating very different regulatory approaches to the products (Abrams et al. 2014; Aktan et al. 2014; Gartner and Malone 2014). In the UK, a key market for the e-cigarette category and the policy debate on their regulation, the division between public health advocates in favour of or opposed to e-cigarettes came to the fore following publication of a Public Health England Report (McNeill et al. 2015a, b) endorsing the positive health effects of e-cigarettes and subsequent criticisms from other public health actors (McKee and Capewell 2015a, b; Lancet 2015). 
It is widely accepted that a highly unified advocacy and NGO network, coalescing around a shared policy agenda, has played a key role in delivering advances in tobacco control in recent decades (Gneiting 2015; Wipfli 2015). E-cigarettes can thus be seen as a disruptive force in the field of tobacco policy, problematizing accepted norms of evidence use in decision making and dividing the expert community to which the government had previously been able to turn for clear, coherent guidance in this area.

The issue of e-cigarettes thus offers a highly pertinent case through which to study the process of evidence-use in policy making. Furthermore, the UK is a particularly useful context in which to examine evidence use in e-cigarette debates for four main reasons. First, the UK has a long-standing, and deeply embedded, culture of evidence use in policy making dating back at least to the New Labour Government (Parsons 2002), which has seen norms of evidence use institutionalised in bodies such as the National Institute of Health and Care Excellence (NICE). Second, the idea that health policy should be informed by research evidence is widely accepted, both within policy making circles and amongst the wider public (Cairney and Studlar 2014; Smith 2013). This is reflected in the strong rhetorical commitment to the goal of 'evidence-based' policy amongst both decisionmakers and policy advocates in relation to e-cigarettes. Third, the UK has a strong record on tobacco control and some of the most advanced tobacco control policies in the world (ASH 2007). As elsewhere, this was achieved to a significant extent by the successful advocacy of a well organised and unified public health community, which has been divided by the issue of e-cigarettes. Finally, the UK has been the site of some of the most vehement policy debates on e-cigarettes globally and some of the most bitter disagreements over the nature of the policy challenge posed by e-cigarettes and the guidance offered by the existing research evidence.

\section{E-Cigarette Regulation in the UK}

In EU member-states, many aspects of e-cigarette regulation are decided collectively at the European level. The 2014 Tobacco Products Directive (TPD) which governs the sale and marketing of e-cigarettes in the UK, takes a dual approach in which devices meeting certain criteria (such as the concentration of nicotine solution they contain) may be sold as tobacco products under the auspices of the Directive, whilst others must be licenced as medical devices by the designated national authorities, such as the UK Medicines and Healthcare Products Regulatory Agency (MHRA). This classification determines how their sale, use and marketing are 
regulated, with only medical devices able to make health claims. National governments remain responsible for other areas of e-cigarette policy without cross border effects including minimum purchase ages for e-cigarettes and rules relating to their use in public places. Public Health England have played a prominent role in discussions about the regulation of e-cigarettes (Bauld et al. 2014; Dockrell et al. 2013; McNeill et al. 2015a), including the issue of public use which, following the implementation of the TPD has emerged as a key point of contention between actors (Chapman et al. 2017; Bauld et al. 2016).

\section{Issue Framing and Evidence Informed Policy}

As is argued throughout the current volume, recent contributions to the study of evidence-informed policy making problematise both our understanding of research evidence and evidence use in the policy process, recognising that that there can be multiple bodies of evidence of relevance to a given policy issue, where multiple (and perhaps mutually exclusive) concerns and policy priorities are at stake in the context of finite governmental resources available to address them. The issue of policy framing is, therefore, key to the analysis of the development of e-cigarette policy debates and the role of evidence within these (Van Hulst and Yanow 2016; Koon et al. 2016). The way policy controversies are framed - the specific understanding of what the issue at stake is - will lead different, relevant bodies of evidence to be foregrounded in debates. Equally, frame sponsors - policy advocates promoting particular understanding of policy issues - pursue particular policy agendas and will point to different bodies of evidence as an argumentative too to support their position (Majone 1993).

Disagreements over what the issue is cannot be decided by recourse to evidence, since interlocutors will not agree on what the 'right' issue framing (and thus the relevant body of evidence) is. However, policy actors often misapprehend that they are engaged, not in debates about the facts of the issue, but in a debate about what this issue itself is; how it is defined and which account of that issue prevails (Stone 1989; Bacchi 2009). The process of issue framing and agenda setting is highly political and involves conflicts between competing values, priorities and ideologies in the context of finite resources. In some cases, the competing values at stake in policy debates may be mutually exclusive and come into direct conflict (e.g. concerns over freedoms and civil liberties versus security). At other times, governments may have to decide to prioritise certain issues and 
outcomes over others, and this may be the result of successful discursive strategies by frame sponsors including the provision of evidence to support their claims.

Crucially, policy actors are often unable to see that they and their opponents are talking about fundamentally different things - or understand the policy problem to be something fundamentally different - even where they address what seems to be the 'same' issue through the 'same' vocabulary. As Charles Taylor (1971) comments, arguments over common meanings are often the basis of the most vehement political disputes. Making explicit and recognising the particular perspectives from which we see certain issues - our own biases and preferences that dictate what the issue is for us - has been identified as an essential step in overcoming protracted political controversies in a process of 'frame reflection' (Rein and Schön 1994).

Whilst intractable policy disputes of this kind cannot be resolved by recourse to the 'facts' of the matter or the relevant evidence base; they are nevertheless involve decisions, which must be taken in light of the evidence (Hawkins and Parkhurst 2016). That is to say relevant research evidence is one component feeding into in a complex process of policy decision making. Evidence of the effects of policy problems will inform the prioritisation of issues, but cannot decide this in isolation from other values and contextual variables. Once a policy problem has been identified as a priority requiring a policy response, evidence will inform decisions about how to address an issue in the most (cost) effective way, but evidence alone cannot determine what course of action governments should take. Recognising both the political nature of decisions and the value of evidence to inform policy decisions (e.g. to ensure the efficacy and effectiveness and value for money of competing policy options) requires a more nuanced account of evidence which appreciates the role evidence can and cannot play in the identification and resolution of policy issues.

\section{The UK E-Cigarette Policy Debate}

These insights are of great relevance to the current UK e-cigarette debate in which policy actors often appear to be talking at cross purposes with each other. Whilst the basis of disagreements between policy actors appear to be routed in conflicts over evidence, the source of these disagreements lies in differing interpretations of the policy problem and the objectives of regulatory responses. Within the UK e-cigarette debate, actors have coalesced around what can be termed the 'harm-reduction' and 'population 
health' positons. By definition, the positions set out here and many actors will not fall squarely within either 'camp'. However, they are useful heuristics for discussing the different ways in which the issue is conceptualised and the nature of the controversy which has emerged.

The former consists of people actively involved in research and practise in the field of smoking cessations who prioritise the harm reduction potential of e-cigarettes for current smokers unwilling or unable to quit tobacco smoking. The logic of their position is that smokers may be able to transition away from smoking through e-cigarettes, reducing health harms experienced. The latter consist of people working in the broader areas of tobacco control and public health who prioritise concerns about the potentially negative population level effects of e-cigarettes and its potential to undermine current tobacco control policies. In addition, they question their efficacy as quit aids and assert the needs for a precautionary approach. Actors in both camps strongly assert the need for evidence based policy making, citing evidence which supports their position (cf. McNeill et al. 2015b; McKee and Capewell 2015a). The quality and policy implications of new studies which appear are highly contested.

The debates within the public health community are not conducted in isolation. There are other prominent participants in these regulatory debates whose concerns and interests overlap and contrast with those of the public health voices at different times in the debate. In particular, there is a prominent and apparently well organised e-cigarette user or 'vaper' movement which has engaged in policy debates to represent their preferences and interests as consumers. The transnational tobacco industry, which has aggressively entered the UK and global e-cigarette markets, has also sought to represent its interests in the debates. This is a source of great controversy given the well documented history of tobacco industry involvement both in the subversion of science and policy and in the coopting of researchers and medical practitioners to confer legitimacy on its interventions (Brandt 2012). The presence of the tobacco industry in the debate, and the implications of this for tobacco control, is arguable the greatest source of controversy between different camps in the debate. The remainder of the chapter examines how these fundamentally different issue framings have led to significant disputes between policy actors in these camps and a range of topics relating to e-cigarette regulation: the potential health benefits of e-cigarettes; their classification as medical, tobacco or consumer devices; and the ways in which they should be marketed and smokers and non-smokers. 


\section{The Potential Health Benefits of E-Cigarettes}

Policy debates on e-cigarettes turn on their potential health benefits. However, the way in which this is defined varies between camps. The debate on e-cigarettes has focused principally on the individual level health effects of e-cigarette use, and their harm reduction potential smoking for existing smokers (McNeill and Munafò 2013; Polosa et al. 2013; Cahn and Siegel 2011; Wagener et al. 2012; Riker et al. 2012). Whilst some argue, and cite evidence, that e-cigarettes are a less toxic alternative for smokers (Etter 2013; Wagener et al. 2012; McNeill and Munafò 2013; Polosa et al. 2013; Hajek et al. 2014), others have urged caution given the current uncertainty about their safety, usage patterns and their impact on existing tobacco control policies (Wagener et al. 2012; Taleb and Maziak 2013; Maziak 2014; Chapman 2014a). However, the health implications of long term vaping are uncertain, and it will require longitudinal studies of real world usage to establish its effects (Grana et al. 2014a).

The harm reduction potential of e-cigarettes turns on their ability to attract and retain smokers, who abandon cigarettes entirely, given that even radically reduced rates of smoking carry significant harms (Schane et al. 2010). To the extent that reduction in smoking through dual use with e-cigarettes this a precursor to quit attempts, this may also contribute to public health (Cheong et al. 2007). However, where dual use is continued and reduces quit attempts - through the false perception of reduced harm from decreased smoking or through the added convenience of being ability to 'vape' in smoke free environments - e-cigarette use may increase, not reduce, harm (Chapman 2014b). This in turn requires accurate assessments of usage patterns. Some limited evidence exists that e-cigarettes can aid smoking cessation. Whilst Brown et al. (2014) found them to be $60 \%$ more effective than nicotine replacement therapy (NRT) in quit attempts, Bullen et al. (2013) found e-cigarettes to be as effective as NRT. Further studies examine rates of e-cigarettes use (Evans and Hoffman 2014; Etter and Bullen 2014; Bullen et al. 2010, 2013), including amongst certain sub-groups including young people (Durmowicz 2014; Grana et al. 2014a; Maziak 2014) and those with mental health issues (Cummins et al. 2014).

Concerns have also arisen that e-cigarettes may act as a gateway to smoking, or entice ex-smokers to return to nicotine use (Zeller and Hatsukami 2009; Fairchild et al. 2014; Lee et al. 2014; Dutra and Glantz 2014; Grana et al. 2013; Maziak 2014). Whether the attractiveness of vaping (and, as will be discussed below, its marketing) to non-smokers is a cause for con- 
cern depends on the assessment of its harmfulness, as well as moral debates about the desirability of marketing a relatively unharmful, yet highly addictive, product such as nicotine to those who do not currently use it.

Those concerned with harm reduction have focussed on the relative toxicity of the e-cigarette vapour in comparison with tobacco smoke, both for consumers of these products and bystanders (Cahn and Siegel 2011; Goniewicz et al. 2013; Cheng 2014; Orr 2014; Callahan-Lyon 2014; Etter et al. 2011). Recent studies have also begun to address issues such as the availability of e-cigarettes (Rose et al. 2014), exposure to marketing (Huang et al. 2014; De Andrade and Hastings 2013a; Grana et al. 2014b) and the effects of that marketing on different groups (Emery et al. 2014; Pepper et al. 2014).

Others, meanwhile, have paid attention to the potential sociological effects of e-cigarettes through the renormalisation of smoking, and the circumvention of existing tobacco control measures, including advertising blackouts and clean air legislation (for exceptions see De Andrade and Hastings 2013a; Fairchild et al. 2014; Maziak 2014; Taleb and Maziak 2013; Zeller and Hatsukami 2009; Henningfield and Zaatari 2010). The similarity in appearance of many e-cigarettes and conventional cigarettes, as well as their packaging (Tobacco Tactics 2014b), may be used as a way for cigarette companies to circumvent cigarette advertising bans. Consequently, current debates appear to prioritise the issue of harm reduction for current smokers over measures designed to prevent the smoking uptake by future generations (Maziak 2014).

\section{Classifying E-Cigarettes}

Where e-cigarettes are legal products available for sale and consumption (e.g. in the UK), regulatory debates have focussed on whether e-cigarettes should be classified as medical devices, consumer goods or tobacco products. Public health advocates have argued in favour of their regulation as medical products, citing the precautionary principle and the absence of studies about their long term health effects. This approach, it is contended, is necessary in order to guarantee their safety and provide a framework for regulating marketing activities. Those favouring a harm reduction approach, meanwhile, have favoured a light-touch regulatory approach, seeing accessibility of products and the ease of transition to vaping as being key drivers of reduced smoking rates (Snowden 2013). Toxicity studies cited in the previous section are cited to support the framing of 
e-cigarettes as a safer alternative and the underline the importance of facilitating the transition of smokers to vaping. Proposals to regulate e-cigarettes as medical devices, it is claimed, both mischaracterise the product and preclude forms of marketing that would attract smokers to migrate to e-cigarettes (Gornall 2012; British American Tobacco 2013; Snowden 2013; Devlin 2012).

E-cigarettes are seen by their proponents as a 'market-led' solution to the smoking issue which must be differentiated form medicalised NRT, like gum or patches (Devlin 2012; Cahn and Siegel 2011; EC Forum Ltd. 2013). From this perspective, e-cigarettes are consumer products, aimed at those wishing to use nicotine recreationally without exposure to cigarette smoke (Snowden 2013). In part, this reflects a desire articulated by vociferous e-cigarette user groups in the debate to be seen not as sick people requiring treatment to recover from smoking, but as consumers choosing safer forms of nicotine consumption.

\section{Marketing}

In keeping with the differing visions of e-cigarettes as medical devices and consumer products, there are widely differing views on the forms of marketing which should be permitted for e-cigarettes. For those who see e-cigarettes as a potentially beneficial, market led phenomenon, attraction to these products through branding and promotion are an essential mechanism for reducing smoking by enticing smokers on to a safer alternative nicotine delivery mechanisms. On the other hand, concerns arise about the attractiveness of e-cigarette marketing for non-smokers and the wider public health effects of the promotion of vaping as a social practise.

E-cigarettes are now widely advertised and promoted online and in national media (Bauld et al. 2014; De Andrade and Hastings 2013b; Tobacco Tactics 2014b). Marketing materials often promote the harm reduction potential of their products for existing smokers (Richardson et al. 2014; De Andrade and Hastings 2013a). Citing the lower recorded level of toxins in e-cigarette vapour versus tobacco smoke (Goniewicz et al. 2013; Schripp et al. 2013), manufacturers claim they cause no long term harm to users, or to the air quality around them (Snowden 2013; Henningfield and Zaatari 2010; Hodgekiss 2013).

Critics have argued that e-cigarette manufacturers have made use of marketing techniques reminiscent of the tobacco industry, including celebrity endorsement and product placement in films and music videos 
(Tobacco Tactics 2014b; De Andrade and Hastings 2013a). The proliferation of e-cigarette marketing via social media (Fallin et al. 2012; Grana et al. 2011), the introduction of flavoured products and claims that e-cigarettes are 'healthier' and environmentally friendly (Yamin et al. 2010; Fallin et al. 2012) have raised concerns they may be especially attractive to young consumers. Recent attempts to repackage and rebrand e-cigarettes, as "vapesticks" or brightly coloured "hookah pens," may be also appeal to youth (Richtel 2014). However, existing studies suggest levels of youth e-cigarette use remain low (McNeill et al. 2014).

\section{Discussion and Conclusion}

In the UK, significant divisions have opened up between policy actors highlighting the potentially positive and negative health effects of e-cigarette use and citing evidence which supports their positions. This issue has become particularly divisive within a public health community which had previously collaborated effectively on a consensual policy agenda.

A defining characteristic of this debate is the extent to which the lines of contestation are defined in terms of evidence and a strong normative commitment by actors on all sides to the goal of evidence based policy making. Policy actors on all sides point to evidence supporting their position and express frustration at the failure of others to follow the apparently self-evident policy prescriptions which follow from this. The apparent failure of their interlocutors to accept the facts presented and their policy consequences has led to accusations of bad faith and conflicts of interest to explain what is otherwise incomprehensible intransigence.

The analysis above compares the different positions articulated on specific aspects of the e-cigarette debate by policy actors and the evidence cited to support these. The two broad camps identified within the public health community are necessarily simplified interpretations of what is a more complex and nuanced array of different views but the division identified between the 'harm reduction' and 'public health' positions serves to demonstrate that different, at times mutually exclusive, positions on an issue such as e-cigarette policy can be support by relevant bodies of evidence. This is particularly the case with such novel products for which the research literature related to key policy issue is necessarily limited. It is erroneous, however, to assume that the current impasse can be overcome simply through the production of more evidence. In some instances, such as the long term health effects of e-cigarette use, consensus may emerge 
(as with the health effects of smoking) which deligitimises or marginalises certain policy positions. However, evidence alone will not be sufficient to resolve what are political and value driven controversies.

Instead, what is needed to overcome the current divisions within public health, and with this a more coherent approach to developing effective and appropriate public policy, is a more explicit recognition of the political nature of the policy process and the possibility that multiple, competing framings of policy objects exist through a process of 'frame reflection' (Rein and Schön 1994). This may seem intuitive to social scientists, particularly those working in the realm of interpretative policy analysis. However, it is far more challenging for many public health actors whose training in the natural sciences perhaps does not equip them to recognise the existence of multiple competing narratives (and evidence bases) as a precursor to the process of frame reflection needed to overcome disputes. The natural science work on the assumptions of a single, universal 'truth', epistemologically accessible through the application of the correct methodology to the relevant data. The idea that there can be multiple interpretations of the same policy issue, multiple bodies of relevant evidence depending on those interpretations may run counter to their professional identities and their scholarly training. It may lead them to be oblivious to, or reject, the idea that there are multiple, competing 'truths' or problem definitions as a dangerous compromise or subversion of the scientific enterprise. However, this process of reflexivity about one's own position and assumptions which underpins processes of frame reflection, which will be essential in attempting to detoxify current debates and open up a space for engagement between actors at different ends of the debate.

\section{REFERENCES}

Abrams et al. 2014. Statement from specialists in nicotine science and public health policy [Online]. Available: http://www.webcitation.org/6ULpMDtvW. Accessed 8 Aug 2014.

Aktan et al. 2014. 129 public health and medical authorities from 31 countries write WHO DG Chan urging evidence-based approach to ecigs [Online]. Available: http://www.webcitation.org/6ULpRXpPJ. Accessed 8 Aug 2014.

ASH. 2007. UK tops the latest EU tobacco control league table [Online]. Available: http://ash.org.uk/media-and-news/press-releases-media-and-news/uk-topsthe-latest-eu-tobacco-control-league-table/. Accessed 12 May 2017. 
Bacchi, C. 2009. Analysing policy: What's the problem representation to be. Frenchs Forest: Pearson Education.

Bauld, L., K. Angus, and A.M. De. 2014. E-cigarette uptake and marketing: A report commissioned by Public Health England. Public Health England. Public Health England.

Bauld, L., A. Mcneill, P. Hajek, J. Britton, and M. Dockrell. 2016. E-cigarette use in public places: Striking the right balance. Tobacco Control, https://doi. org/10.1136/tobaccocontrol-2016-053357.

Brandt, A.M. 2012. Inventing conflicts of interest: A history of tobacco industry tactics. American Journal of Public Health 102: 63-71.

British American Tobacco. 2013. A focus on harm Reuction: Why it matters [Online]. Available: http://www.webcitation.org/6ULgu6oo3. Accessed 6 Nov 2013.

Brown, J., E. Beard, D. Kotz, S. Michie, and R. West. 2014. Real-world effectiveness of e-cigarettes when used to aid smoking cessation: A cross-sectional population study. Addiction 109: 1531.

Bullen, C., H. Mcrobbie, S. Thornley, M. Glover, R. Lin, and M. Laugesen. 2010. Effect of an electronic nicotine delivery device (e cigarette) on desire to smoke and withdrawal, user preferences and nicotine delivery: Randomised cross-over trial. Tobacco Control 19: 98-103.

Bullen, C., C. Howe, M. Laugesen, H. Mcrobbie, V. Parag, J. Williman, and N. Walker. 2013. Electronic cigarettes for smoking cessation: A randomised controlled trial. The Lancet 382: 1629-1637.

Cahn, Z., and M. Siegel. 2011. Electronic cigarettes as a harm reduction strategy for tobacco control: A step forward or a repeat of past mistakes. Journal of Public Health Policy 32: 16-31.

Cairney, P., and D. Studlar. 2014. Public health policy in the United Kingdom: After the war on tobacco, is a war on alcohol brewing? World Medical er Health Policy 6: 308-323.

Callahan-Lyon, P. 2014. Electronic cigarettes: Human health effects. Tobacco Control 23: ii36-ii40.

Chapman, S. 2013. Should electronic cigarettes be as freely available as tobacco cigarettes? No. British Medical Journal 346. Available: https://doi.org/10.1136/ bmj.f3840.

- 2014a. E-cigarettes: Does the new emperor of tobacco harm reduction have any clothes? The European Journal of Public Health. https://doi. org/10.1093/eurpub/cku054.

- 2014b. E-cigarettes: The best and the worst case scenarios for public health-An essay by Simon Chapman. British Medical Journal 349: g5512.

Chapman, S., M. Daube, and W. Maziak. 2017. Should e-cigarette use be permitted in smoke-free public places? No. Tobacco Control 26: e3-e4. 
Cheng, T. 2014. Chemical evaluation of electronic cigarettes. Tobacco Control 23: iill-iil7.

Cheong, Y., H.-H. Yong, and R. Borland. 2007. Does how you quit affect success? A comparison between abrupt and gradual methods using data from the International Tobacco Control Policy Evaluation Study. Nicotine \& Tobacco Research 9: 801-810.

Cummins, S.E., S.-H. Zhu, G.J. Tedeschi, A.C. Gamst, and M.G. Myers. 2014. Use of e-cigarettes by individuals with mental health conditions. Tobacco Control 23: iii48-iii53.

De Andrade, M., and G. Hastings. 2013a. The marketing of e-cigarettes: A quick snapshot. Cancer Research UK.

.2013b. Tobacco harm reduction and nicotine containing products: Research priorities and policy directions. Social Marketing. Cancer Research UK.

Devlin, K. 2012. Response to BMA Briefing [Online]. Available: http://www.ecita. org.uk/blog/index.php/response-to-bma-briefing/. Accessed 24 Jan 2014.

Dockrell, M., R. Morrison, L. Bauld, and A. McNeill. 2013. E-cigarettes: Prevalence and attitudes in Great Britain. Nicotine and Tobacco Research 15: $1737-1744$.

Durmowicz, E.L. 2014. The impact of electronic cigarettes on the paediatric population. Tobacco Control 23: ii4l-ii46.

Dutra, L.M., and S.A. Glantz. 2014. Electronic cigarettes and conventional cigarette use among US adolescents: A cross-sectional study. JAMA Pediatrics 168: 610.

EC Forum Ltd. 2013. The E-cigarette summit: Science, regulation and public health, November 12. London: The royal Society.

Emery, S.L., L. Vera, J. Huang, and G. Szczypka. 2014. Wanna know about vaping? Patterns of message exposure, seeking and sharing information about e-cigarettes across media platforms. Tobacco Control 23: iiil7-iii25.

Etter, J.-F. 2013. Should electronic cigarettes be as freely available as tobacco? Yes. British Medical Journal 346: f3845.

Etter, J.-F., and C. Bullen. 2014. A longitudinal study of electronic cigarette users. Addictive Behaviors 39: 491-494.

Etter, J.-F., C. Bullen, A.D. Flouris, M. Laugesen, and T. Eissenberg. 2011. Electronic nicotine delivery systems: A research agenda. Tobacco Control 20: 243-248.

Evans, S.E., and A.C. Hoffman. 2014. Electronic cigarettes: Abuse liability, topography and subjective effects. Tobacco Control 23: ii23-ii29.

Fairchild, A.L., R. Bayer, and J. Colgrove. 2014. The renormalization of smoking? E-cigarettes and the tobacco "endgame". New England Journal of Medicine 370: 293.

Fallin, A., N.L. York, and E.J. Hahn. 2012. Tips for managing a social networking site. Tobacco Control 21: 507-508. 
Gartner, C., and R.E. Malone. 2014. Duelling letters: Which one would you sign? Tobacco Control 23: 369-370.

Gneiting, U. 2015. From global agenda-setting to domestic implementation: Successes and challenges of the global health network on tobacco control. Health Policy and Planning. https://doi.org/10.1093/heapol/czv001.

Goniewicz, M.L., J. Knysak, M. Gawron, L. Kosmider, A. Sobczak, J. Kurek, A. Prokopowicz, M. Jablonska-Czapla, C. Rosik-Dulewska, and C. Havel. 2013. Levels of selected carcinogens and toxicants in vapour from electronic cigarettes. Tobacco control. https://doi.org/10.1136/tobaccocontrol-2012-050859.

Gornall, J. 2012. Electronic cigarettes: Medical device or consumer product? British Medical Journal 345: e6417.

Grana, R.A., S.A. Glantz, and P.M. Ling. 2011. Electronic nicotine delivery systems in the hands of Hollywood. Tobacco Control 20: 425-426.

Grana, R., N. Benowitz, and S.A. Glantz 2013. Background paper on E-cigarettes (electronic nicotine delivery systems). San Francisco: Center for Tobacco Control and Research and education.

Grana, R.A., P.M. Ling, N. Benowitz, and S. Glantz. 2014a. Electronic cigarettes. Circulation 129: e490-e492.

Grana, R.A., L. Popova, and P.M. Ling. 2014b. A longitudinal analysis of electronic cigarette use and smoking cessation. JAMA Internal Medicine 174: 812-813.

Hajek, P., J.F. Etter, N. Benowitz, T. Eissenberg, and H. Mcrobbie. 2014. Electronic cigarettes: Review of use, content, safety, effects on smokers and potential for harm and benefit. Addiction 109: 1801.

Hawkins, B., and J. Parkhurst. 2016. The 'good governance' of evidence in health policy. Evidence \& Policy 12 (4): 575-592. https://doi.org/10.1332/174426 $415 \times 14430058455412$.

Henningfield, J., and G. Zaatari. 2010. Electronic nicotine delivery systems: Emerging science foundation for policy. Tobacco Control 19: 89-90.

Hodgekiss, A. 2013. Advert that claims electronic cigarette is 'completely harmless' banned as misleading [Online]. London. Available: http://www.dailymail. co.uk/health/article-2262868/Advert-claims-electronic-cigarettecompletely-harmless-banned-misleading.html. Accessed 23 Aug 2013.

Huang, J., R. Kornfield, G. Szczypka, and S.L. Emery. 2014. A cross-sectional examination of marketing of electronic cigarettes on Twitter. Tobacco Control 23: iii26-iii30.

Koon, A.D., B. Hawkins, and S.H. Mayhew. 2016. Framing and the health policy process: A scoping review. Health Policy and Planning. https://doi.org/10.1093/ heapol/czvl28.

Lancet, T. 2015. E-cigarettes: Public Health England's evidence-based confusion. Lancet 386: 829. 
Lee, S., R.A. Grana, and S.A. Glantz. 2014. Electronic cigarette use among Korean adolescents: A cross-sectional study of market penetration, dual use, and relationship to quit attempts and former smoking. Journal of Adolescent Health 54: 684-690.

Majone, G. 1993. Evidence argument and persuasion in the policy process. New Haven: Yale University Press.

Manning, S. 2013. British American Tobacco enters electronic cigarette market in Britain with the 'Vype' [Online]. London. Available: http://www.independent. co.uk/news/uk/home-news/british-american-tobacco-enters-electroniccigarette-market-in-britain-with-the-vype-8737286.html. Accessed 21 Aug 2013.

Maziak, W. 2014. Harm reduction at the crossroads: The case of E-cigarettes. American Journal of Preventive Medicine 47: 505-507.

McKee, M., and S. Capewell. 2015a. Electronic cigarettes: We need evidence, not opinions. The Lancet 386: 1239.

- 2015b. Evidence about electronic cigarettes: A foundation built on rock or sand? British Medical Journal 351: h4863.

McNeill, A., and M.R. Munafò. 2013. Reducing harm from tobacco use. Journal of Psychopharmacology 27: 13-18.

McNeill, A., J.F. Etter, K. Farsalinos, P. Hajek, J. Houezec, and H. Mcrobbie. 2014. A critique of a WHO-commissioned report and associated article on electronic cigarettes. Addiction 109: 2128.

McNeill, A., L. Brose, R. Calder, S. Hitchman, P. Hajek, and H. Mcrobbie. 2015a. E-cigarettes: An evidence update. Public Health England 1-113. Available: https://assets.publishing.service.gov.uk/government/uploads/system/ uploads/attachment_data/file/457102/Ecigarettes_an_evidence_update_A_ report_commissioned_by_Public_Health_England_FINAL.pdf.

McNeill, A., L.S. Brose, R. Calder, S.C. Hitchman, P. Hajek, and H. Mcrobbie. 2015b. E-cigarettes: The need for clear communication on relative risks. The Lancet 386: 1237.

Orr, M.S. 2014. Electronic cigarettes in the USA: A summary of available toxicology data and suggestions for the future. Tobacco Control 23: iil 8-ii22.

Parsons, W. 2002. From muddling through to muddling up-evidence based policy making and the modernisation of British government. Public Policy and Administration 17: 43-60.

Pepper, J.K., S.L. Emery, K.M. Ribisl, B.G. Southwell, and N.T. Brewer. 2014. Effects of advertisements on smokers' interest in trying e-cigarettes: The roles of product comparison and visual cues. Tobacco Control 23: iii31-iii36.

Polosa, R., B. Rodu, P. Caponnetto, M. Maglia, and C. Raciti. 2013. A fresh look at tobacco harm reduction: The case for the electronic cigarette. Harm Reduction Journal 10: 19. 
Rein, M., and D. Schön. 1994. Frame reflection. Towards the resolution of intractable policy controversies. New York: Basic Books.

Richardson, A., O. Ganz, and D. Vallone. 2014. Tobacco on the web: Surveillance and characterisation of online tobacco and e-cigarette advertising. Tobacco Control. https://doi.org/10.1136/tobaccocontrol-2013-0501246.

Richtel, M. 2013. The E-cigarette Inductry, waiting to exhale [Online]. New York Times. Available: http://www.webcitation.org/6ULp7z7IL. Accessed 1 Nov 2013.

- 2014. E-cigarettes, by other names, lure young and worry experts [Online]. New York Times. Available: http://www.nytimes.com/2014/03/05/ business /e-cigarettes-under-aliases-elude-the-authorities.html?_r=0. Accessed 31 Mar 2014.

Riker, C.A., K. Lee, A. Darville, and E.J. Hahn. 2012. E-cigarettes: Promise or peril? Nursing Clinics of North America 47: 159-171.

Rose, S.W., D.C. Barker, H. D'angelo, T. Khan, J. Huang, F.J. Chaloupka, and K.M. Ribisl. 2014. The availability of electronic cigarettes in US retail outlets, 2012: Results of two national studies. Tobacco Control 23: iiil0-iiil6.

Schane, R.E., P.M. Ling, and S.A. Glantz. 2010. Health effects of light and intermittent smoking. Circulation 121: 1518-1522.

Schripp, T., D. Markewitz, E. Uhde, and T. Salthammer. 2013. Does e-cigarette consumption cause passive vaping? Indoor Air 23: 25-31.

Smith, K. 2013. Beyond evidence based policy in public health: The interplay of ideas. Basingstoke: Palgrave Macmillan.

Smithers, R. 2014. Whether they're called 'e-cigarettes' or 'vaporisers' the market is heating up [Online]. The Guardian. Available: http://www.theguardian. com/business/2014/jun/26/e-cigarettes-market-vaporisers. Accessed 8 Aug 2014.

Snowden, C. 2013. Free market approaches to public health: The case of nicotine [Online]. London: Institute of Economic Affairs. Available: http://www.iea. org.uk/sites/default/files/publications/files/Free\%20 Market $\% 20$ Solutions\%20in\%20Health.pdf. Accessed 20 Aug 2013.

Stone, D.A. 1989. Causal stories and the formation of policy agendas. Political Science Quarterly 104: 281-300.

Taleb, Z.B., and W. Maziak. 2013. Harm reduction and e-cigarettes: Not evidencebased. Regulation 14: 1027.

Taylor, C. 1971. Interpretation and the sciences of man. The Review of Metaphysics 25: 3-51.

Thesing, G. 2014. Imperial Tobacco's Cooper adds Blu to take e-cigarette leap [Online]. Bloomberg Business Week. Available: http://www.businessweek.com/ news /2014-07-15/imperial-tobacco-ceo-cooper-adds-blu-to-take-ecigarette-leap. Accessed 8 Aug 2014. 
Tobacco Tactics. 2014a. E-cigarettes [Online]. Tobacco Tactics. Available: http:// www.tobaccotactics.org/index.php/E-cigarettes. Accessed 19 Sept 2014.

- 2014b. E-cigarettes: Marketing [Online]. Available: http://www. tobaccotactics.org/index.php/E-cigarettes:_Marketing. Accessed 19 Sept 2014.

Van Hulst, M., and D. Yanow. 2016. From policy "frames" to "framing" theorizing a more dynamic, political approach. The American Review of Public Administration 46: 92-112.

Wagener, T.L., M. Siegel, and B. Borrelli. 2012. Electronic cigarettes: Achieving a balanced perspective. Addiction 107: 1545-1548.

Wipfli, H. 2015. The global war on tobacco. Baltimore: Johns Hopkins University Press.

World Health Organization. 2014. Electronic nicotine delivery systems: Report by WHO [Online]. Available: http://apps.who.int/gb/fctc/PDF/cop6/FCTC_ COP6_10-en.pdf?ua=1. Accessed 17 Sept 2014.

Yamin, C.K., A. Bitton, and D.W. Bates. 2010. E-cigarettes: A rapidly growing internet phenomenon. Annals of Internal Medicine 153: 607-609.

Zeller, M., and D. Hatsukami. 2009. The strategic dialogue on tobacco harm reduction: A vision and blueprint for action in the US. Tobacco Control 18: 324-332.

Zhu, S.-H., J.Y. Sun, E. Bonnevie, S.E. Cummins, A. Gamst, L. Yin, and M. Lee. 2014. Four hundred and sixty brands of e-cigarettes and counting: Implications for product regulation. Tobacco Control 23: iii3-iii9.

Open Access This chapter is licensed under the terms of the Creative Commons Attribution 4.0 International License (http://creativecommons.org/licenses/ by $/ 4.0 /$ ), which permits use, sharing, adaptation, distribution and reproduction in any medium or format, as long as you give appropriate credit to the original author(s) and the source, provide a link to the Creative Commons license and indicate if changes were made.

The images or other third party material in this chapter are included in the chapter's Creative Commons license, unless indicated otherwise in a credit line to the material. If material is not included in the chapter's Creative Commons license and your intended use is not permitted by statutory regulation or exceeds the permitted use, you will need to obtain permission directly from the copyright holder.

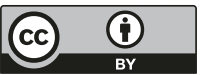

